\title{
Reproducibility and validity of Londrina ADL Protocol in people with multiple sclerosis with light and moderate disability
}

Reprodutibilidade e validade do Londrina ADL Protocol em pessoas com esclerose múltipla com incapacidade leve e moderada

Reproducibilidad y validez del Londrina ADL Protocol en personas con esclerosis múltiple con leve y moderada discapacidad

Heloisa Galdino Gumieiro Ribeiro

ORCID: https://orcid.org/0000-0002-8175-1740 Universidade Pitágoras Unopar, Brazil Centro Universitário Filadélfia, Brazil Universidade Estadual de Londrina, Brazil E-mail: heloisa.ribeiro@unifil.br

Viviane de Souza Pinho Costa

ORCID: https://orcid.org/0000-0002-6988-6917 Pontifícia Universidade Católica do Paraná, Brazil E-mail: viviane.pinho@pucpr.br

Michelle Moreira Abujamra Fillis ORCID: https://orcid.org/0000-0002-7457-3229 Universidade Estadual do Norte do Paraná, Brazil E-mail: micmoreira@gmail.com

Thainá Bessa Alves

ORCID: https://orcid.org/0000-0002-9814-9377

Universidade Pitágoras Unopar, Brazil

Universidade Estadual de Londrina, Brazil E-mail: thainaa.bessa@gmail.com Vitória Cavalheiro Puzzi ORCID: https://orcid.org/0000-0002-3696-056X Universidade Pitágoras Unopar, Brazil Universidade Estadual de Londrina, Brazil E-mail: vitoriapuzzi@hotmail.com

Gabriela Alves dos Santos

ORCID: https://orcid.org/0000-0001-7410-760X Centro Universitário Filadélfia, Brazil E-mail: gabrielaalves@edu.unifil.br

Karina Perez Porto

ORCID: https://orcid.org/0000-0001-5270-7305 Centro Universitário Filadélfia, Brazil

E-mail: karina_perez_porto@hotmail.com

Bruno Mastellini Trevisan

ORCID: https://orcid.org/0000-0001-8872-043X Centro Universitário Filadélfia, Brazil

E-mail: bruno.mastellini@ hotmail.com

Joice Mara de Oliveira

ORCID: https://orcid.org/0000-0003-3387-2940 Universidade Pitágoras Unopar, Brazil Universidade Estadual de Londrina, Brazil E-mail: joice.mara.oli@gmail.com Karina Couto Furlanetto

ORCID: https://orcid.org/0000-0002-7496-7228 Universidade Pitágoras Unopar, Brazil State University of Londrina, Brazil E-mail:ka_furlanetto@hotmail.com

\begin{abstract}
People with multiple sclerosis (MS) commonly present negative impacts on activities of daily living (ADLs) with the disease progression. However, there is no instrument with measured metric properties specifically for use in people with MS. Objective: To verify the reproducibility and validity of the Londrina ADL Protocol (LAP) to assess ADLs in people with MS. Methods: Individuals diagnosed with ME presenting mild or moderate disability according to the
\end{abstract}


Expanded Disability Status Scale (EDSS) performed the LAP in three moments (intra-rater and inter-rater) following standardized recommendations. Physical activity level was used as validation criterion and was assessed by the pedometer which counts steps/day during seven consecutive days. Results: Twenty-three individuals (48\% women, 39 \pm 9.2 years, diagnosis time: $9.9 \pm 5.5$ years) with EDSS $2.5 \pm 1.0$ points were included. The LAP was reproducible intra-rater and inter-rater (Intraclass Correlation Coefficient [ICC] $=0.86$ and 0.72 , respectively); however, participants demonstrated a learning effect of $-6.6 \pm 8.4 \%$. There was a significant correlation between the LAP and the number of steps/day $(\mathrm{r}=-0.556, \mathrm{p}=0.014)$. Conclusion: The Londrina ADL Protocol is a promised reproducible and valid instrument that can be used for the objective assessment of ADLs in people with MS.

Keywords: Multiple sclerosis; Daily activities; Motor activity.

\section{Resumo}

Introdução: Pessoas com esclerose múltipla (EM) comumente apresentam impactos negativos nas atividades de vida diária (AVDs) com a progressão da doença. No entanto, não há nenhum instrumento com propriedades métricas medidas especificamente para uso em pessoas com EM. Objetivo: Verificar a reprodutibilidade e validade do Londrina ADL Protocol (LAP) para avaliação de AVD em pessoas com EM. Métodos: Indivíduos com EM com incapacidade leve ou moderado segundo a Expanded Disability Status Scale (EDSS) realizaram o LAP em três momentos (intraexaminador e interexaminador) seguindo recomendações padronizadas. O nível de atividade física foi utilizado como critério de validação e foi avaliado pelo pedômetro que conta passos/dia durante sete dias consecutivos. Resultados: Vinte e três indivíduos (48\% mulheres, $39 \pm$ 9,2 anos, tempo de diagnóstico: 9,9 \pm 5,5 anos) com EDSS 2,5 \pm 1,0 pontos foram incluídos. O LAP foi reprodutível intra-avaliador e inter-avaliador (coeficiente de correlação intraclasse $[\mathrm{ICC}]=0,86$ e 0,72 , respectivamente); no entanto, os participantes demonstraram um efeito de aprendizagem de $-6,6 \pm 8,4 \%$. Houve correlação significativa entre o LAP e o número de passos/dia $(\mathrm{r}=-0,556, \mathrm{p}=$ 0,014). Conclusão: O Londrina ADL Protocol é um instrumento promissor reprodutível e válido para a avaliação de AVDs em pessoas com EM.

Palavras-chave: Esclerose múltipla; Atividades diárias; Atividade motora.

\section{Resumen}

Introducción: Las personas con esclerosis múltiple (EM) comúnmente tienen impactos negativos en las actividades de la vida diaria (AVD) a medida que avanza la enfermedad. Sin embargo, no existe ningún instrumento con propiedades métricas específicamente medidas para su uso en personas con EM. Objetivo: Verificar la reproducibilidad y validez del Londrina ADL Protocol (LAP) para la evaluación de AVD en personas con EM. Métodos: Los individuos con EM con discapacidad leve o moderada de acuerdo con la Expanded Disability Status Scale (EDSS) realizaron el LAP en tres momentos (intra e inter-examinador) siguiendo las recomendaciones estandarizadas. El nivel de actividad física se utilizó como criterio de validación y se evaluó mediante un podómetro que cuenta pasos/día durante siete días consecutivos. Resultados: Se incluyeron 23 sujetos (48\% mujeres, $39 \pm$ 9,2 años, tiempo al diagnóstico: 9,9 \pm 5,5 años) con EDSS 2,5 \pm 1,0 puntos. El LAP fue reproducible intra e interevaluador (coeficiente de correlación intraclase $[\mathrm{CCI}]=0,86$ y 0,72 , respectivamente); sin embargo, los participantes demostraron un efecto de aprendizaje de $-6,6 \pm$ $8,4 \%$. Hubo una correlación significativa entre LAP y el número de pasos/día $(r=-0,556, p=0,014)$. Conclusión: El Londrina ADL Protocol es un instrumento prometedor, reproducible y válido para la evaluación de las AVD en personas con EM.

Palabras clave: Esclerosis multiple; Actividades diarias; Actividad motora.

\section{Introduction}

Multiple sclerosis (MS) is an inflammatory, demyelinating, autoimmune disease that affects the central nervous system (Machado, Almeida, Perla \& Scheffer, 2017). People with MS may present heterogeneous clinical conditions and a progressive worsening is observed in many cases. On the other hand, signs and symptoms, such as mild fatigue can suddenly change into severe impact on motor control, leading to different disabilities as well as resulting in death due to the disease (Oliveira-Kumakura, Bezutti, Silva \& Gasparino, 2019; Ferreira, Lima, Vasconcelos, Lana-Peixoto \& Haase, 2011).

Individuals with MS commonly present changes in their work, family, self-care and leisure routine, which directly affect the performance of their activities of daily living (ADLs) (Mansson \& Lexell, 2004). Therefore, a precise evaluation of health conditions is essential. Questionnaires and functional tests have been widely used to assess people with MS and the Expanded Disability Status Scale (EDSS) is the most used test to assess clinical control of the disease (Kurtzke, 1983; Cohen, Kessler \& Fischer, 1993). This is a largely used scale which focus on disability and gait assessments while is also considered an extensive and time consuming tool (Machado, Almeida, Perla \& Scheffer, 2017; Cohen, Kessler \& Fischer, 1993). Other 
tests, such as the Timed up and go (TUG) and the Timed Walking of 25 feet (T25) are also used to assess functionality of these patients; however, all the above mentioned tests do not reflect performance in ADLs (Sebastião, Sandroff \& Learmonth, 2016; Motl et al., 2017; Mendes, Tilbery, Balsimelli, Moreira \& Cruz, 2001).

To the best of our knowledge, only subjective tools to assess ADLs in people with MS are available in the scientific literature, such as the Barthel Index or the Katz Index (Einarsson, Gottberg, Fredrikson, Koch \& Holmqvist, 2006). But the common variation of mood, anxiety and depression aspects of this population, as well as the memory requirement of questionnaires may limit the accurate evaluation of ADLs. These factors explain the need for tests that objectively quantify ADLs in individuals with MS (Ferreira, Lima, Vasconcelos, Lana-Peixoto \& Haase, 2011).

We hypothesized that an objective tool, initially developed to assess ADLs of elderly subjects as well as individuals with Chronic Obstructive Pulmonary Disease (COPD), might be valid and reproducible to quantify ADLs in individuals with MS. The Londrina Activities of Daily Living Protocol (Londrina ADL Protocol), also known as LAP (Sant'Ánna et al., 2017; Paes et al., 2017) quantify ADLs in a standardized circuit of five common daily living activities including lower and upper limbs movements. Therefore, this study aimed to investigate the reproducibility and validity of LAP in individuals with MS.

\section{Methodology}

\subsection{Sample and design}

This is a cross-sectional study, composed by individuals with diagnosis of multiple sclerosis. Participants were recruited by the invitation to people registered in the Londrina Association of People with Multiple Sclerosis (ALPEM), as well as from the local community and among recruitment "snowball" type. Prior to data collection, this study was approved by ethics and research committee with studies on human (CAAE 04557418.6.0000.5217).

The inclusion criteria were: being at least 18 years old; with at least 6 months of medical diagnosis of MS following the classification by McDonald (Polman et al., 2011); who were not in an outbreak of the disease and have maintained regular treatment for at least 3 months; absence of physical limitations due to orthopedic conditions as well as use wheelchair; without any other severe or unstable self-reported disease which could make the proposed tests impossible to perform. The exclusion criteria were: being unable to carry out all the proposed assessments; or who did not have a minimum cognitive aspect classified as median assessed by the Brief International Cognitive Assessment for Multiple Sclerosis (BICAMS) scale (Spedo et al., 2015).

Data collection was carried out between March 2019 and February 2020 at the Physiotherapy Clinic of the University Center Filadelfia (UniFil) or at Pitágoras Unopar University (UNOPAR). The evaluations were previously scheduled by telephone and carried out in 2 visits spaced by approximately 10 days apart. In the first visit, anthropometric and sociodemographic characteristics were obtained. Secondly, each participant performed the LAP three times (intra and interrater) to assess performance in ADLs. Fatigue was assessed by the Modified Fatigue Impact Scale (MFIS), perception of walking by the Multiple Sclerosis Walking Scale-12 (MSWS-12) and independence in daily activities by the Barthel Index. Physical activity in daily life (PADL) was assessed by the International Physical Activity Questionnaire (IPAQ) on the first visit and also by the pedometer which was wore during one week to count number of steps. On their second visit, functional capacity was assessed by the TUG and the T25, disability level was assessed by the EDSS and exercise capacity by the 6minute walk test (6MWT).

\subsection{Assessments}


The Londrina ADL Protocol (Sant'Ánna et al., 2017; Paes et al., 2017) is an objective test composed by five stations (Figure 1) in which standardized activities should be performed consecutively in usual pace, to reflect real life (Figure 2). The main outcome of the LAP is the total time (seconds) of the whole circuit, and a stopwatch was used to record it. However, time spent in each station was also recorded during the circuit (without interruptions) and it was used as another outcome (LAP station). The LAP was performed 3 times. The same rater (intra-rater) performed the first two tests and a second rater performed the third (inter-rater). The following physiological variables were measured before and after each LAP: heart rate (HR), peripheral oxygen saturation ( $\mathrm{SpO} 2)$, dyspnea and fatigue sensation by the Borg scale (3) and systolic and diastolic blood pressure. A minimum interval of 30 minutes between the tests were considered and the next LAP only started when physiological variables returned to the level assessed at the beginning of the test. The LAP reference values were calculated according to the predictive equation proposed by Paes et al. (2017).

Figure 1. Flowchart of the sample.

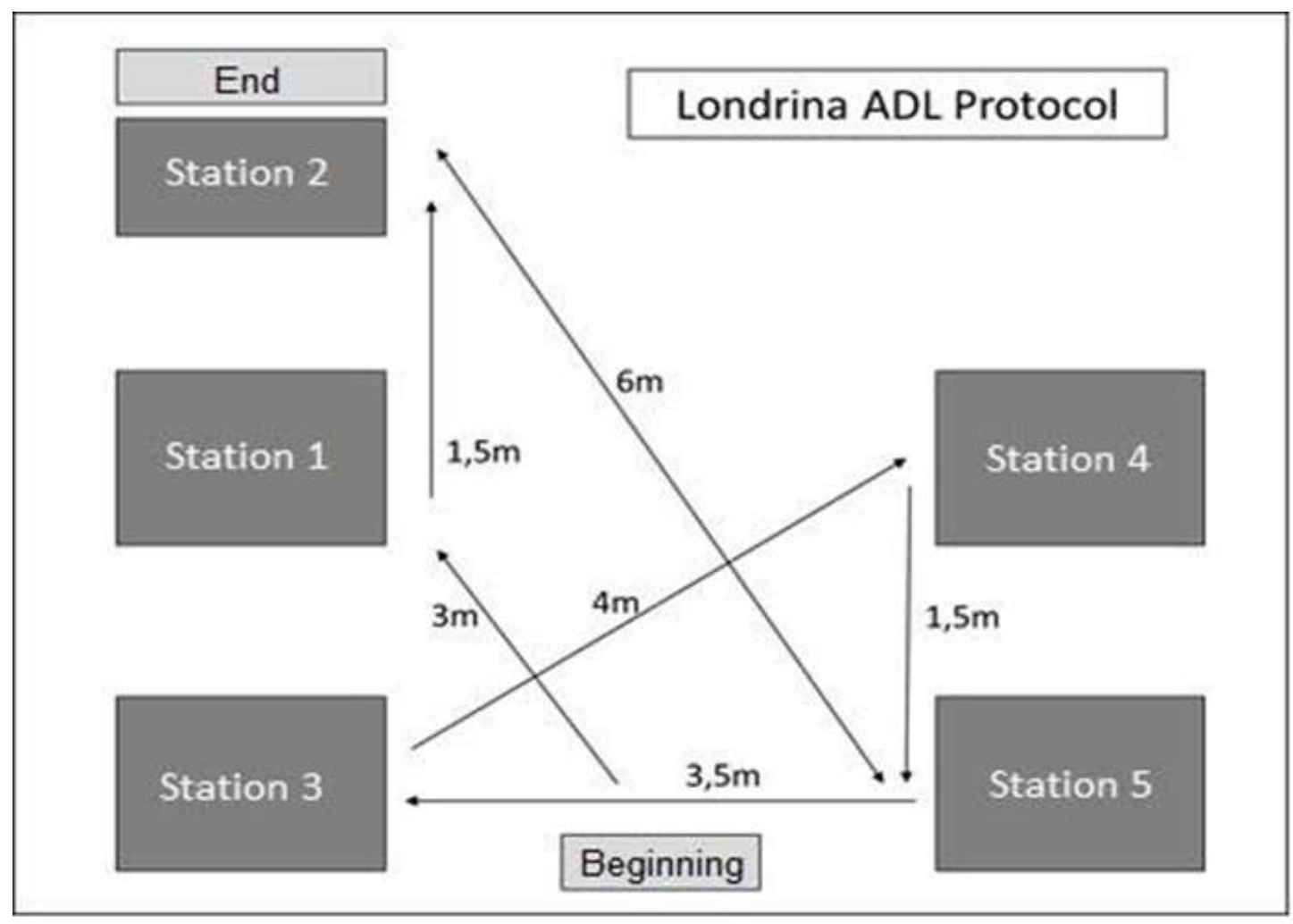

Source: This figure was developed by the authors and adapted from Sant'Anna et al. (2017).

The performance of activities that reflect daily life in each LAP station follows a pre-specified routine, where the evaluated person was instructed to perform all activities and to walk from one station to the other at usual pace to reflect their performance in real life (Sant’Ánna et al., 2017). Each station is described as follows:

1) Table objects: This activity reflects the movements of the upper limbs in a sitting position. A person sits on a chair in front of a table, which is divided in half, separated by two halves, preferably $1.2 \mathrm{~m}$ long and $0.6 \mathrm{~m}$ wide. On the left side of the table there are ten objects, four with $250 \mathrm{~g}$, four with $500 \mathrm{~g}$ and two with $1 \mathrm{~kg}$. The subject is instructed to take, with their hands, one object at a time and place it on the right side of the table. After this step, the participant must return all objects back, in the same way. There is no standardization for the choice of objects. 
2) Walking with bags: This activity represents activities of carrying loads while walking, inside and outside the house. A person walks on a $6 \mathrm{~m}$ course three times, totaling $18 \mathrm{~m}$ of walking, holding a bag with $5 \%$ of their body weight on each hand.

3) Shelves: This activity is expressed as activities of the upper limbs without support associated with the orthostatic position. The subject stands in front of a shelf with four floors, positioned at different levels, one above the other (distance between the floor and the first shelf, $42 \mathrm{~cm}$; distance from one shelf to the next, $45 \mathrm{~cm}$ ), with a table next to them. On the table, there were 12 objects, four with $250 \mathrm{~g}$, four with $500 \mathrm{~g}$, two with $1 \mathrm{~kg}$ and two with $2 \mathrm{~kg}$. The aim was to take the objects, one by one, with both hands, and put them on the shelves, in no defined order. The participant organizes the objects on the shelves in such a way that 3 objects are placed on each shelf. After placing all objects on the shelves, they must be return them to the same table, one by one, also using both hands.

4) Clothesline: This station was proposed to reflect unsupported upper limbs activities in the orthostatic position, in which the performance of more intense movements of the trunk is possible, occasionally, to remain in squatting posture (in case participant choose this movement). A person stands in front of a clothesline, positioned at eye level, with a basket or bowl positioned on the ground next to the subject which contains 10 items of clothing of different sizes for adults (weight range of the items $80-442 \mathrm{~g}$ ). The subject must take all items, one by one, with both hands and put it on the clothesline. After hanging all items of clothing, the subject must place the items back inside the basket or bowl, one by one and with both hands. The order and positioning of the items on the clothesline were chosen by the subject.

5) Walking: This activity should be perform as a walk in daily life. A person must walk again at least 6 meters three times in a row, but without load on the upper limbs. 
Figure 2. Standardized positioning of Londrina Activities of Daily Living Protocol stations.

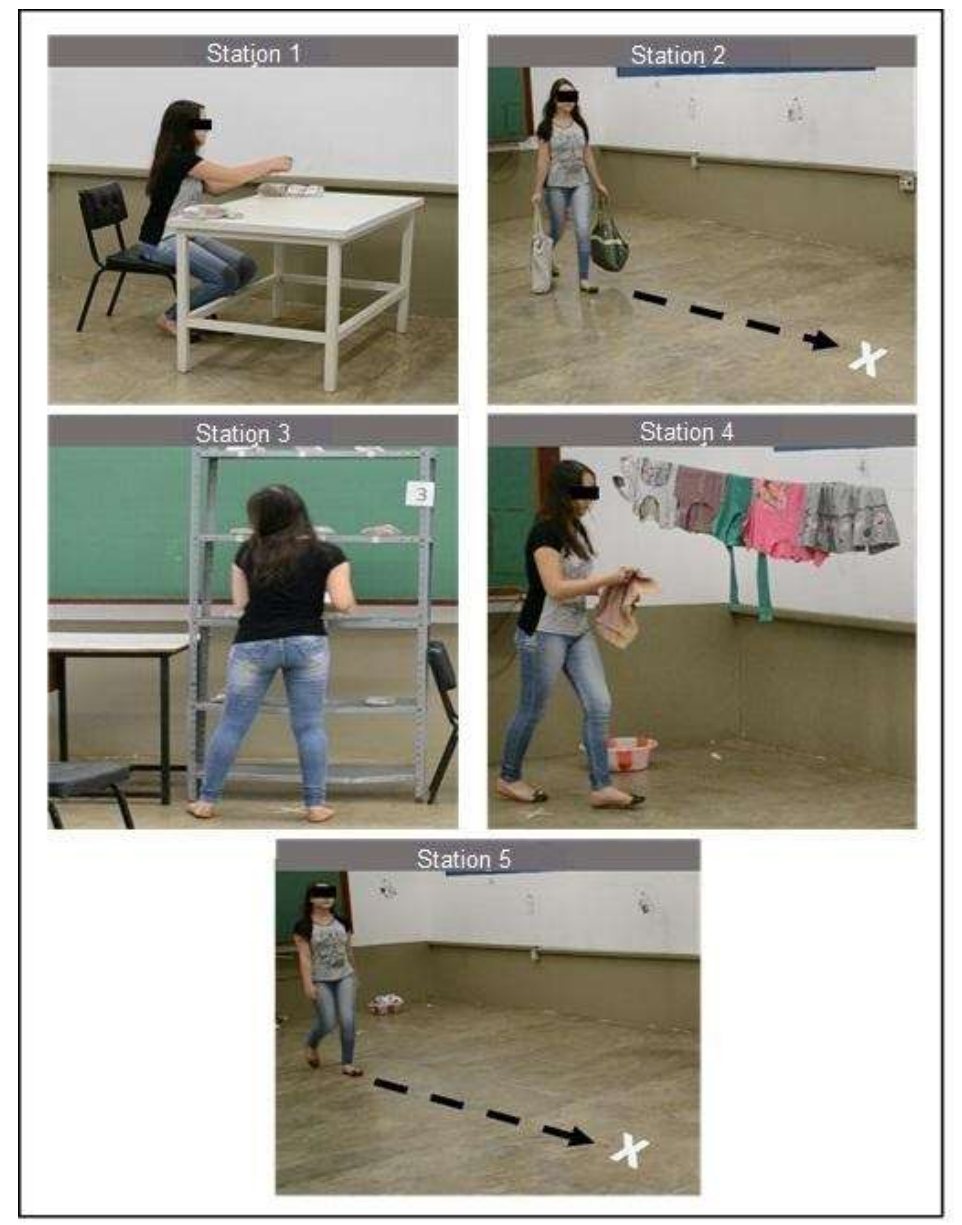

Source: This figure was developed by the authors and adapted from Sant'Anna et al. (2017).

\section{Anthropometric and sociodemographic data}

Gender, age, time of diagnosis, treatment and employment were recorded in face-to-face interviews. Anthropometric data, such as height $(\mathrm{cm})$ and body weight $(\mathrm{Kg})$ were measured and BMI was calculated.

\section{Physical Activity in Daily Life (PADL)}

For an objective assessment of physical activity level, participants were instructed to wear the pedometer (SW-200 Digiwalker, Yamax, Tokyo, Japan) for 7 consecutive days during the awake time (Crouter, Schneider, Karabulut \& Basset, 2003; Gosney, Scott, Snook \& Molt, 2007). The device was positioned on the right side at waist level and the subjects were instructed to maintain their daily routine. At the end of the day, the number of steps was recorded in a diary (Gosney, Scott, Snook \& Molt, 2007; Sandroff et al., 2012). The use of the pedometer for 7 days and for at least 8 hours/day were considered as valid measures (Gosney, Scott, Snook \& Molt, 2007; Demeyer et al., 2014). The average of steps/day considering five weekdays, as well as the average of steps/day of week+weekend days were the outcomes used.

Subjective assessment of physical activity level was performed using the IPAQ, short version, which consists of eight questions (Gosney, Scott, Snook \& Molt, 2007; Matsudo et al., 2001).

\section{Functional capacity}

Disabilities of MS was assessed by the EDSS in which a score ranging from 0 to 10 reflects eight functional systems: 
pyramidal, cerebella, brain stem, sensor, visceral, bowel movements, visual and mental functions, as well as other functions. To note, mild and moderate disability scores range from 0 to 3.5 and from 4 to 6 points, respectively (Kurtzke, 1983; Cohen, Kessler \& Fischer, 1993).

The TUG test was performed to reflect mobility and balance (Sebastião, Sandroff \& Learmonth, 2016; Podsiadlo \& Richardson, 1991). The participant was instructed to stand up from a chair, walk towards and turn around a cone positioned at the 3-meter mark, walk back to the chair and sit down again (Podsiadlo \& Richardson, 1991). Three repetitions were performed, with an interval of at least 1 minute between them and the best value was considered.

The T25 test was used for measuring lower limbs performance (Motl et al., 2017). In this test, participants must walk 7.62 meters as fast as possible. Two consecutive tests were made and the shorter time in seconds was considered (Motl et al., 2017; Kaufman, Moyer \& Norton, 2000).

Two 6-minute walk tests were performed following the American Thoracic Society / European Respiratory Society guidelines (Holland et al., 2014). The percentage of the predicted was calculated according to the reference values proposed by Britto et al. (2013).

\section{Questionnaires}

Fatigue was assessed using the Modified Fatigue Impact Scale (MFIS) (Lopes, Lavado, Kallaur \& Oliveira, 2014) which consists of 21 questions, arranged in three domains: physical, cognitive, and psychosocial (Lopes, Lavado, Kallaur \& Oliveira, 2014; Pavan et al., 2007).

The Barthel Index was used to assess individual's independence from ten activities of daily living (Minosso, Amendola, Alvarenga \& Oliveira, 2010). This index has been used as a measure for physical dependence in individuals with multiple sclerosis (Einarsson, Gottberg, Fredrikson, Koch \& Holmqvist, 2006).

The Multiple Sclerosis Walking Scale - 12 (MSWS-12) is a questionnaire that was used to identify the impact of MS on walking. It contains 12 questions, with scores between 0 and 80 . The higher the value, the worse the walk performance (Nogueira, Baitelli, Alvarenga \& Thuler, 2012).

\subsection{Statistical analysis}

The analyzes were performed using the statistical programs SPSS 22.0 (SPSS, Chicago, Illinois) and GraphPad Prism 6 (GraphPad La Jolla Software, California). Data were presented in absolute and relative frequency, mean and standard deviation or median and interquartile range $25-75 \%$. The Shapiro-Wilk test was used to verify data normality while the MannWhitney test and the Friedman test with Dunn's post-hoc test were used for comparisons.

Reproducibility was analyzed using the intraclass correlation coefficient (ICC) (Koo \& $\mathrm{Li}, 2016$ ) and the Bland \& Altman plots were constructed to visualize intra-rater and inter-rater agreement. Absolute and relative standard error of measurement (SEM and SEM\%), absolute and relative values of minimum detectable change (MDC and MDC\%), and learning effect were also calculated (Mesquita, 2016).

Spearman's correlations were used to validate the LAP with the average number of steps/day, and correlations between the total LAP, LAP stations and other evaluated variables were also analyzed (Dancey \& Reidy, 2007). The ChiSquare test with Yates' correction was also performed to verify the association between categorical variables. The level of statistical significance was set as $\mathrm{p}<0.05$.

\section{Results}

Seventy-nine eligible individuals with MS were identified, but the sample analyzed consisted by 23 people with mild 
and moderate disability (Figure 3). The main anthropometric and sociodemographic characteristics are shown in Table 1 while physical-functional characteristics are shown in Table 2. The comparisons between mild and moderate levels of disability assessed by the EDSS showed that TUG, T25 and 6MWT were significant better in people with mild levels of disability (Table 3). Comparisons between genders are also available in the Table 4.

Figure 3. Londrina ADL Protocol stations with activities. Station 1: Table objects; station 2: walking with bags; station 3: shelves; station 4: clothesline shelves; station 5: walking.

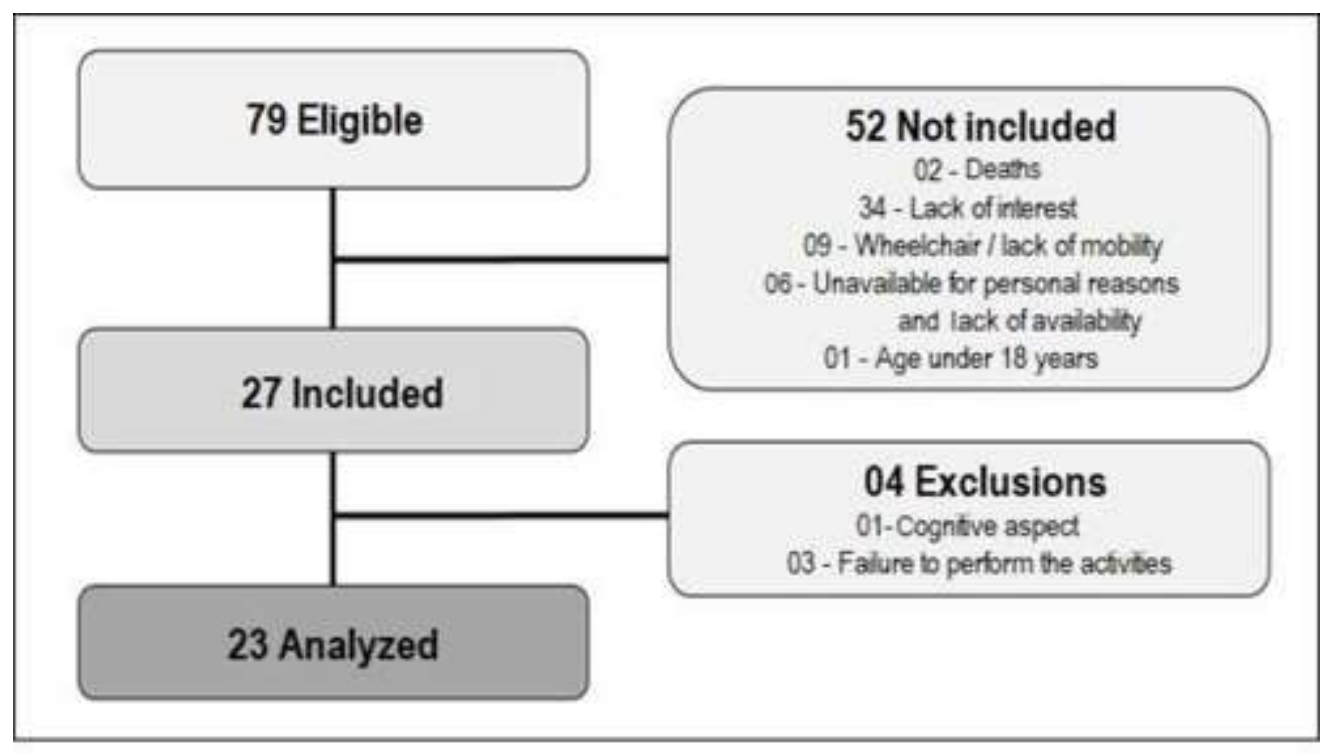

Source: This figure was developed by the authors.

Table 1. Anthropometric and sociodemographic characteristics of the studied population:

\begin{tabular}{lc}
\hline & $\mathrm{N}=23$ \\
\hline Gender. M/F (\%) & $12 / 11(52 / 48)$ \\
Age (years) & $39 \pm 9$ \\
Height $(\mathrm{m})$ & $1.67 \pm 0.07$ \\
Weight $(\mathrm{kg})$ & $74.8 \pm 16.9$ \\
BMI $\left(\mathrm{kg} / \mathrm{m}^{2}\right)$ & $25.6 \pm 5.15$ \\
Time of MS diagnosis (years) & $9.9 \pm 5.5$ \\
Work. yes/no $(\%)$ & $15 / 8(65 / 35)$ \\
Number of outbreaks & $5 \pm 4$ \\
Treatment - MS. yes/no $(\%)$ & $21 / 2(91 / 9)$ \\
\hline
\end{tabular}

The data were presented in absolute and relative values, mean and standard deviation; M: male; F: female; m: meters; kg: kilograms; BMI: body mass index; $\mathrm{kg} / \mathrm{m}^{2}$ : kilogram per square meter; TreatmentMS: if any specific drug treatment for multiple sclerosis is performed. Source: This table was developed by the authors. 
Research, Society and Development, v. 11, n. 2, e19611225494, 2022

(CC BY 4.0) | ISSN 2525-3409 | DOI: http://dx.doi.org/10.33448/rsd-v11i2.25494

Table 2. Physical-functional characteristics of patients included in the study.

\begin{tabular}{lc}
\hline & Total \\
& $(\mathrm{n}=23)$ \\
\hline Total LAP (s) & $307[281-342]$ \\
LAP 1st station (s) & $39[30-43]$ \\
LAP 2nd station (s) & $21[19-25]$ \\
LAP 3rd station (s) & $59[52-63]$ \\
LAP 4th station (s) & $139[122-156]$ \\
LAP 5th station (s) & $17[15-19]$ \\
LAP predicted (s) & $250[235-285]$ \\
LAP (\% predicted) & $117[107-139]$ \\
No steps in weekdays & $4939[4480-6311]$ \\
$N^{o}$ steps in the week+weekend days week+ & $4873[4506-7048]$ \\
weekend days +week+weekend days & $5.85[5.39-7.44]$ \\
TUG (s) & $5.36[4.70-6.66]$ \\
6MWT (m) & $535[467-606]$ \\
6MWT (\% predicted) & $89[76-95]$ \\
MFIS (points) & $42[20-67]$ \\
Barthel (points) & $95[90-100]$ \\
MSWS-12 (points) & $13[3-33]$ \\
EDSS (points) & $2.5[2.0-3.5]$ \\
\hline
\end{tabular}

The data were presented as absolute and relative value, median and interquartile range $25 \%-75 \%$. LAP: Londrina Activities of Daily Living Protocol; LAP predicted: value in seconds predicted to perform the LAP; LAP (predicted\%): percentage of predicted LAP performed by the patient; $\mathrm{N}^{\circ}$ steps in weekdays: average number of steps taken from Monday to Friday; No steps in the week: average number of steps performed 7 days a week; TUG: Timed up and go test; T25: Timed Walking of 25 feet; 6MWT (m): six-minute walk test; 6MWT (\% predicted): percentage of predicted 6-minute walk test performed by the patient; EDSS: Expanded Disability Status Scale. MFIS: by the Modified Fatigue Impact Scale; Barthel: Barthel index; MSWS-12: Multiple Sclerosis Walking Scale -12 . Source: This table was developed by the authors. 
Research, Society and Development, v. 11, n. 2, e19611225494, 2022

(CC BY 4.0) | ISSN 2525-3409 | DOI: http://dx.doi.org/10.33448/rsd-v11i2.25494

Table 3. Physical-functional characteristics of subjects included in the study separated by EDSS level.

\begin{tabular}{|c|c|c|c|}
\hline & $\begin{array}{l}\text { Mild EDSS } \\
\quad(\mathrm{n}=19)\end{array}$ & $\begin{array}{l}\text { Moderate EDSS } \\
\quad(n=04)\end{array}$ & $\mathrm{p}$ value \\
\hline Total LAP (s) & 307 [281-342] & 313 [284-417] & 0.61 \\
\hline LAP 1st station (s) & 39 [32-43] & $36[30-42]$ & 0.68 \\
\hline LAP 2nd station (s) & 20 [19-22] & $26[22-30]$ & $0.02 *$ \\
\hline LAP 3rd station (s) & $57[52-62]$ & 63 [49-65] & 0.42 \\
\hline LAP 4th station (s) & 140 [122-156] & $129[101-228]$ & 0.65 \\
\hline LAP 5th station (s) & $17[15-18]$ & 20 [15-22] & 0.13 \\
\hline LAP predicted (s) & 247 [235-275] & 277 [240-306] & 0.28 \\
\hline LAP ( $\%$ predicted $)$ & 117 [107-136] & $127[95-152]$ & 0.58 \\
\hline $\mathrm{N}^{\mathrm{o}}$ steps weekdays & $5278[4494-6311]$ & $4476[3191-7908]$ & 0.42 \\
\hline $\mathrm{N}^{\mathrm{o}}$ steps week+weekend days & $5255[4506-7048]$ & 4913 [3373-7809] & 0.54 \\
\hline \multicolumn{4}{|l|}{ IPAQ (points) } \\
\hline Work, yes / no (\%) & $14 / 5(74 / 26)$ & $1 / 3(25 / 75)$ & 0.08 \\
\hline Hours worked (hours) & $8[0-10]$ & $0[0-7,5]$ & 0.19 \\
\hline Years of study (years) & $17[15-18]$ & $14.5[11-15.7]$ & 0.10 \\
\hline Vigorous activities (days) & $2[1-3]$ & $2[0-3]$ & 0.75 \\
\hline Vigorous activities (min) & $45[20-75]$ & $50[10-82]$ & 1.00 \\
\hline Moderate activity (days) & $3[2-6]$ & $1[0-6]$ & 0.61 \\
\hline Moderate activity (min) & 60 [15-90] & $30[0-150]$ & 0.44 \\
\hline Walking (days) & $2[0-5]$ & $0[0-2]$ & 0.28 \\
\hline Walking (min) & $30[0-120]$ & $0[0-30]$ & 0.20 \\
\hline Useful sitting (min) & 480 [240-600] & 420 [195-825] & 0.92 \\
\hline Sitting on weekends (min) & $360[240-480]$ & $660[375-855]$ & 0.06 \\
\hline TUG (s) & $5.62[5.18-6.59]$ & $8.12[6.24-8.86]$ & $0.04 *$ \\
\hline $\mathrm{T} 25(\mathrm{~s})$ & $5.15[4.56-6.00]$ & $7.12[6.12-8.18]$ & $0.01 *$ \\
\hline $6 \mathrm{MWT}(\mathrm{m})$ & 544 [494-617] & 431 [338-509] & $0.02 *$ \\
\hline 6MWT (\% predicted) & 92 [82-99] & $75[55-89]$ & 0.07 \\
\hline MFIS (points) & $37[11-51]$ & $59[20-77]$ & 0,27 \\
\hline Barthel (points) & $95[90-100]$ & 92 [86-98] & 0,28 \\
\hline MSWS-12 (points) & $11[3-26]$ & $51[31-64]$ & $0,008^{*}$ \\
\hline EDSS (points) & $2.0[1.5-3.0]$ & $4.0[4.0-4.5]$ & 0.0001 \\
\hline
\end{tabular}

The data were presented as absolute and relative value, median and interquartile range $25 \%-75 \%$. LAP: Londrina Activities of Daily Living Protocol; LAP predicted: value in seconds predicted to perform the LAP; LAP (predicted\%): percentage of predicted LAP performed by the patient; $\mathrm{N}^{\circ}$ steps working days: average number of steps taken from Monday to Friday; No steps in the week: average number of steps performed 7 days a week; TUG: Timed up and go test; T25: Timed Walking of 25 feet; 6MWT (m): six-minute walk test; 6MWT (\% predicted): percentage of predicted 6-minute walk test performed by the patient; EDSS: Expanded Disability Status Scale. Source: This table was developed by the authors. 
Table 4. Physical-functional characteristics of subjects included in the study and separated by gender.

\begin{tabular}{|c|c|c|c|}
\hline & $\begin{array}{c}\text { Men } \\
(\mathrm{n}=12)\end{array}$ & $\begin{array}{l}\text { Woman } \\
(\mathrm{n}=11) \\
\end{array}$ & $P$ value \\
\hline LAP total (s) & $326[316-361]$ & $281[268.5-298.7]$ & 0.02 \\
\hline LAP $1^{\mathrm{a}}$ station $(\mathrm{s})$ & 39 [33-43] & $39[28-42]$ & 0.97 \\
\hline LAP $2^{\mathrm{a}}$ station $(\mathrm{s})$ & 22 [19-28] & 19 [18-22] & 0.13 \\
\hline LAP $3^{\mathrm{a}}$ station $(\mathrm{s})$ & $62[51-65]$ & $55[51-61]$ & 0.26 \\
\hline LAP $4^{\mathrm{a}}$ station $(\mathrm{s})$ & 149 [138-175] & $120[100-140]$ & 0.03 \\
\hline LAP $5^{\text {a }}$ station $(\mathrm{s})$ & 17 [14-20] & $17[15-18]$ & 0.85 \\
\hline Predicted LAP (s) & $247[232-280]$ & 257 [238-303] & 0.44 \\
\hline LAP ( $\%$ predicted) & $128[114-140]$ & 109 [96-117] & 0.01 \\
\hline $\mathrm{N}^{\mathrm{o}}$ steps weekdays & 4939 [4066-6624] & 5093 [4546-6689] & 0.74 \\
\hline $\mathrm{N}^{\mathrm{o}}$ steps week+weekend days & 4873 [4525-6967] & 4968 [4273-7239] & 0.80 \\
\hline \multicolumn{4}{|l|}{ IPAQ (points) } \\
\hline Work, yes / no (\%) & $7 / 5(58 / 42)$ & $8 / 3(72 / 28)$ & 0.47 \\
\hline Hours worked (hours) & $4.0[0.0-9.0]$ & $6.5[0.0-10.5]$ & 0.68 \\
\hline Years of study (years) & 15 [12-17] & $16.7[15-19.2]$ & 0.22 \\
\hline Vigorous activities (days) & $3[1-3.5]$ & $2[0-3]$ & 0.36 \\
\hline Vigorous activities (min) & $60[12.5-82.5]$ & $52.5[0-63.7]$ & 0.68 \\
\hline Moderate activity (days) & $2[0-4]$ & $3[1.5-7]$ & 0.64 \\
\hline Moderate activity (min) & $60[0-180]$ & $60[15-90]$ & 0.75 \\
\hline Walking (days) & $0[0-3.5]$ & $1.5[0-3]$ & 0.85 \\
\hline Walking (min) & 0 [0-65] & $35[0-75]$ & 0.87 \\
\hline Useful sitting (min) & $540[240-750]$ & $420[225-555]$ & 0.51 \\
\hline Sitting on weekends (min) & $420[240-660]$ & $480[300-495]$ & 0.97 \\
\hline TUG (s) & 5.85 [4.79-7.09] & $5.87[5.40-7.87]$ & 0.87 \\
\hline $\mathrm{T} 25(\mathrm{~s})$ & $5.36[4.20-6.82]$ & $5.29[4.91-6.68]$ & 0.92 \\
\hline 6MWT (m) & 535 [419-611] & 535 [459-597] & 0.52 \\
\hline 6MWT (\%predicted) & $90[69-93]$ & 90 [82-104] & 0.15 \\
\hline MFIS (points) & $44[17-75]$ & $40[22-51]$ & 0.92 \\
\hline Barthel (points) & $95[87-100]$ & 97 [93-100] & 0.87 \\
\hline MSWS-12 (points) & $26[5-41]$ & 9 [2-29] & 0.51 \\
\hline EDSS (points) & $3.0[2.0-4.0]$ & $2.5[1.5-3.5]$ & 0.47 \\
\hline
\end{tabular}

The data were presented as absolute and relative value, median and interquartile range $25 \%-75 \%$. LAP: Londrina Activities of Daily Living Protocol; station: LAP station; Predicted LAP: value in seconds predicted to perform the LAP; LAP (\% predicted): percentage of predicted LAP performed by the patient; $\mathrm{N}^{\circ}$ weekdays steps: average number of steps taken from Monday to Friday; $\mathrm{N}^{\mathrm{o}}$ steps in the week: average number of steps performed on 7 days a week; IPAQ: International Physical Activity Questionnaire; Hours worked: how many hours you work per day; vigorous activities (day): frequency of vigorous activity in the week in days; vigorous activities ( $\mathrm{min}$ ): time in minutes spent in vigorous activity per day; moderate activity (days): frequency of moderate activity in the week in days; moderate activity (min): time in minutes spent on moderate activity per day; Walking (days): frequency of days in the week that walk at least 10 minutes continuously; Walking (min): time in minutes spent walking each day; Useful sitting ( $\mathrm{min})$ : time in minutes that remains seated on working days; Sitting on weekends (min): time in minutes that remains sitting on weekends; EDSS: Expanded Disability Status Scale; TUG: Timed up and go test; T25: Timed Walking of 25 feet; 6MWT (m): 6-minute walk test; 6MWT (\% predicted): percentage of the predicted 6-minute walk test performed by the patient; MFIS: by the Modified Fatigue Impact Scale; Barthel: Barthel index; MSWS-12: Multiple Sclerosis Walking Scale -12 . Source: This table was developed by the authors. 


\section{Reproducibility of the Londrina ADL Protocol}

The comparison of the three tests are shown in Figure 4. No difference was found between LAP 1 and LAP $2(\mathrm{p}=$ 0.055), as well as between LAP 2 and LAP 3 ( $p=0.166)$. In total, 18 patients $(78.3 \%)$ decreased the time spent to perform LAP 2 in relation to LAP 1. Reproducibility occurred with an intra-rater ICC $=0.86(0.49-0.95)$ and inter-rater ICC $=0.72$ (0.08-0.89). In addition, intra-rater LAP analysis showed SEM $=20.62 \mathrm{~s} ; \mathrm{SEM} \%=17 \% ; \mathrm{MCD}=57.15 \mathrm{~s} ; \mathrm{MDC} \%=17 \%$; and Learning effect $=-6.6 \% \pm 8.4 \%$, with a mean difference of $-24.35 \pm 32.87$ seconds. The Bland \& Altman plots (Figure 5) showed the agreement between LAPs as well as the mean differences and 95\% CI.

Figure 4. Comparison between LAP 1, LAP 2 and LAP 3.

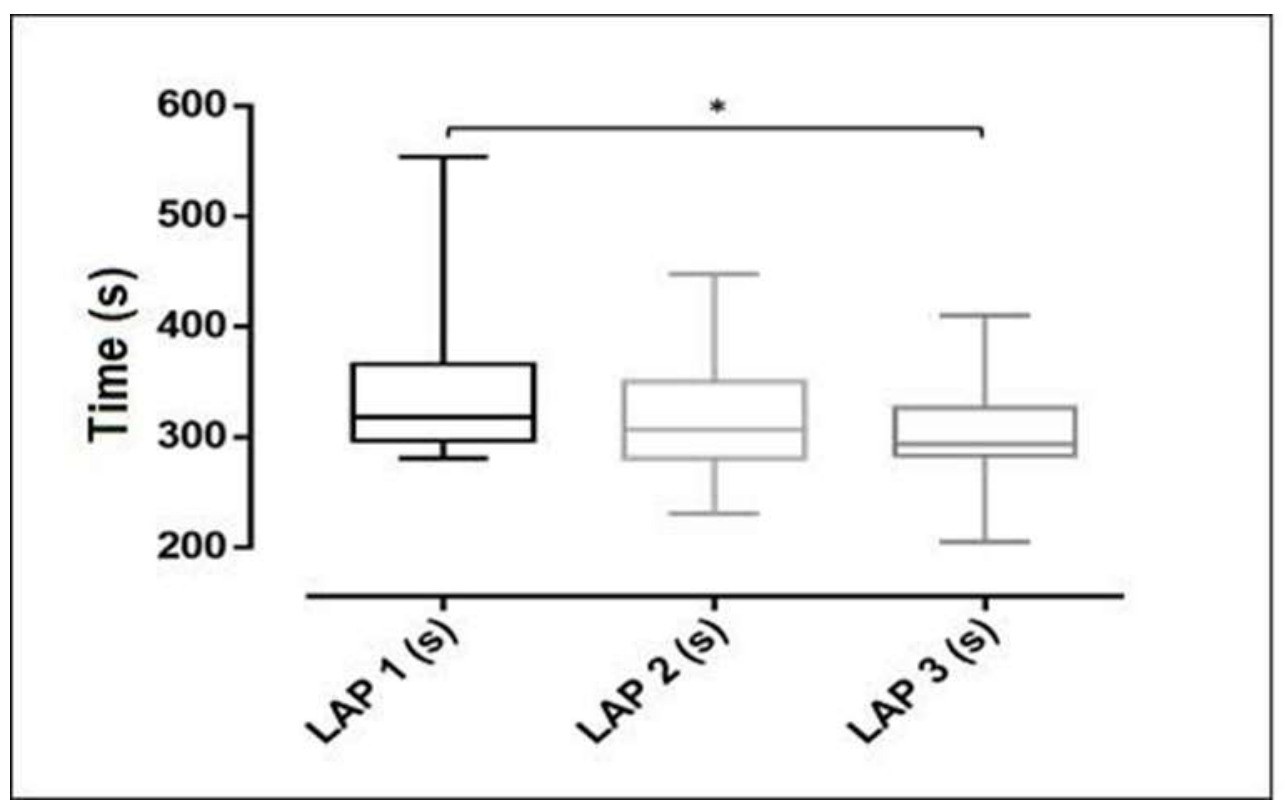

Friedman test: $\mathrm{P}<0.0001$; *Dunn's post-hoc test: $\mathrm{P}<0.05$; LAP 1: first LAP; LAP 2: second LAP; LAP 3: third LAP; s: seconds. LAP: Londrina Activities of Daily Living Protocol. Source: This figure was developed by the authors.

Figure 5. 5a. Bland \& Altman with intra-rater agreement of the Londrina Activities of Daily Living Protocol. 5b. Bland-Altman with the inter-rater agreement of the Londrina Activities of Daily Living Protocol.

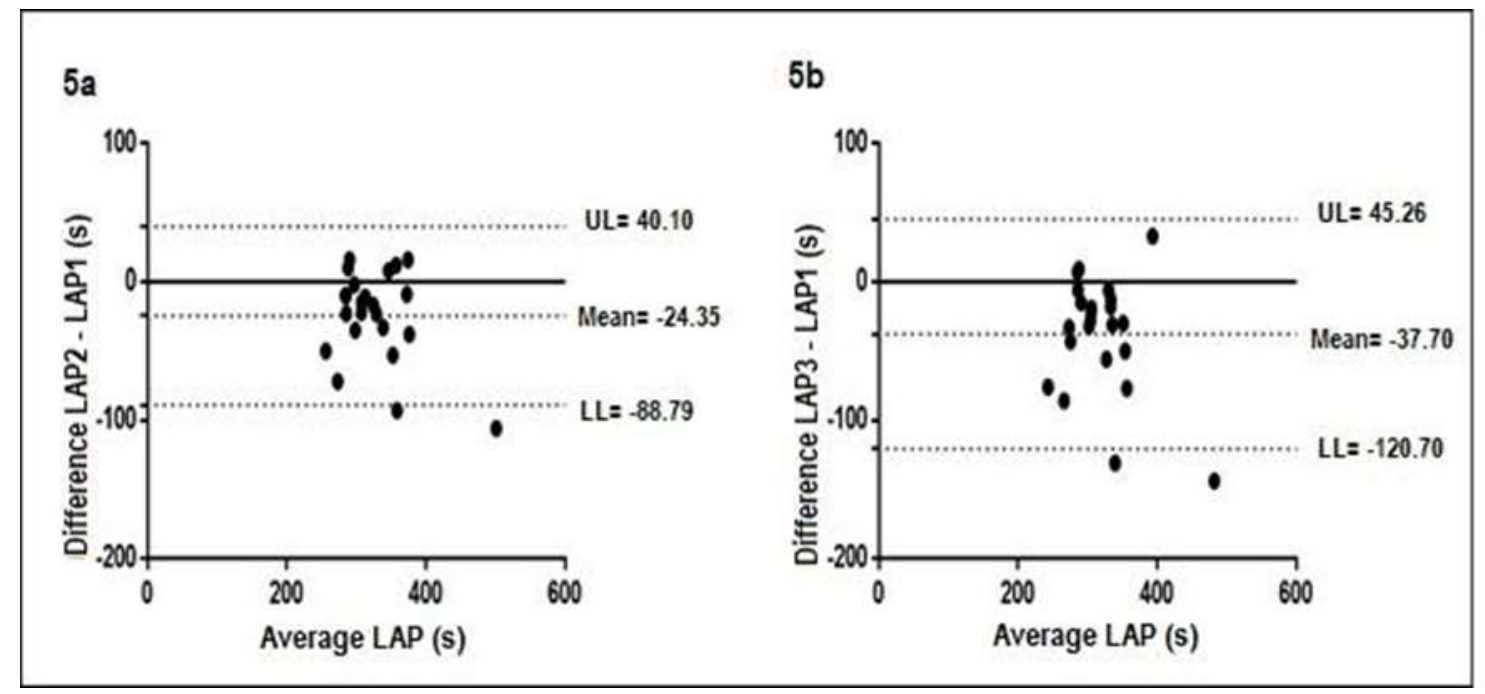

LAP: Londrina Activities of Daily Living Protocol. Source: This figure was developed by the authors. 
The physiological responses obtained during the LAPs are described in Table 5. HR, Borg scale (dyspnea and fatigue) and Systolic Blood Pressure showed significant changes (i.e. before vs after) of each LAP; however, there were no differences in these changes among the three LAPs.

Table 5. Physiological responses during the performance of each LAP.

\begin{tabular}{|c|c|c|c|c|c|c|c|c|c|}
\hline & \multicolumn{3}{|c|}{ LAP1 } & \multicolumn{3}{|c|}{ LAP2 } & \multicolumn{3}{|c|}{ LAP3 } \\
\hline & Before & After & $\begin{array}{c}\mathrm{p} \\
\text { value }\end{array}$ & Before & After & $\begin{array}{c}\mathrm{p} \\
\text { value }\end{array}$ & Before & After & $\begin{array}{c}\mathrm{p} \\
\text { value }\end{array}$ \\
\hline HR (bpm) & $79[71-88]$ & 93 [77-107] & $<0.0001$ & $\begin{array}{c}78[64- \\
88]\end{array}$ & $\begin{array}{c}93[84- \\
104]\end{array}$ & $<0.0001$ & 78 [68-85] & $\begin{array}{c}93[84- \\
107]\end{array}$ & $<0.0001$ \\
\hline $\begin{array}{l}\text { Borg dyspnea } \\
\text { (points) }\end{array}$ & $0[0-1]$ & $1[0.5-2]$ & 0.001 & $0.5[0-1]$ & $1[0.5-2]$ & 0.001 & $0[0-0.5]$ & $1[0.5-2]$ & 0.001 \\
\hline $\begin{array}{l}\text { Borg upper limbs } \\
\text { (points) }\end{array}$ & $0[0-1]$ & $1[0-3]$ & 0.004 & $0.5[0-2]$ & $1[0-3]$ & 0.009 & $0.5[0-2]$ & $0.5[0-3]$ & 0.02 \\
\hline $\begin{array}{l}\text { Systolic blood } \\
\text { pressure }(\mathrm{mmHg})\end{array}$ & $\begin{array}{c}120[110- \\
126]\end{array}$ & $\begin{array}{l}130[120- \\
140]\end{array}$ & $<0.0001$ & $\begin{array}{c}120[110- \\
122]\end{array}$ & $\begin{array}{c}128[110- \\
140]\end{array}$ & 0.006 & $\begin{array}{l}120[110- \\
120]\end{array}$ & $\begin{array}{c}124[120- \\
138]\end{array}$ & 0.006 \\
\hline $\begin{array}{l}\text { Diastolic blood } \\
\text { pressure }(\mathrm{mmHg})\end{array}$ & 80 [70-86] & 82 [78-88] & 0.08 & $\begin{array}{c}80[70- \\
90]\end{array}$ & 80 [70-90] & 0.31 & 80 [70-90] & $\begin{array}{c}80[70- \\
90]\end{array}$ & 0.21 \\
\hline
\end{tabular}

The data were presented as absolute and relative value, median and interquartile range $25 \%-75 \%$. LAP: Londrina Activities of Daily Living Protocol; HR: heart rate, bpm: beats per minute; $\mathrm{SpO}_{2}$ : peripheral oxygen saturation; Borg dyspnea: referred sensation of dyspnea on the Borg scale; Borg upper limbs: referred sensation of fatigue of the upper limbs by the Borg scale; Borg lower limbs: referred sensation of fatigue of lower limbs by the Borg scale; $\mathrm{mmHg}$ : millimeters of mercury. Source: This taable was developed by the authors.

\section{Londrina ADL Protocol validation}

Moderate correlations were found between the time spent in LAP and the number of steps/day during weekdays as well as with the number of steps/day duringn the week+weekend days (Figure 6). Furthermore, the LAP was also correlated with the percentage of the predicted performed in the 6MWT $(r=-0.474 ; \mathrm{P}=0.020)$. 
Figure 6. Correlation between LAP (seconds) and the number of steps/day during weekdays and week+weekend days.

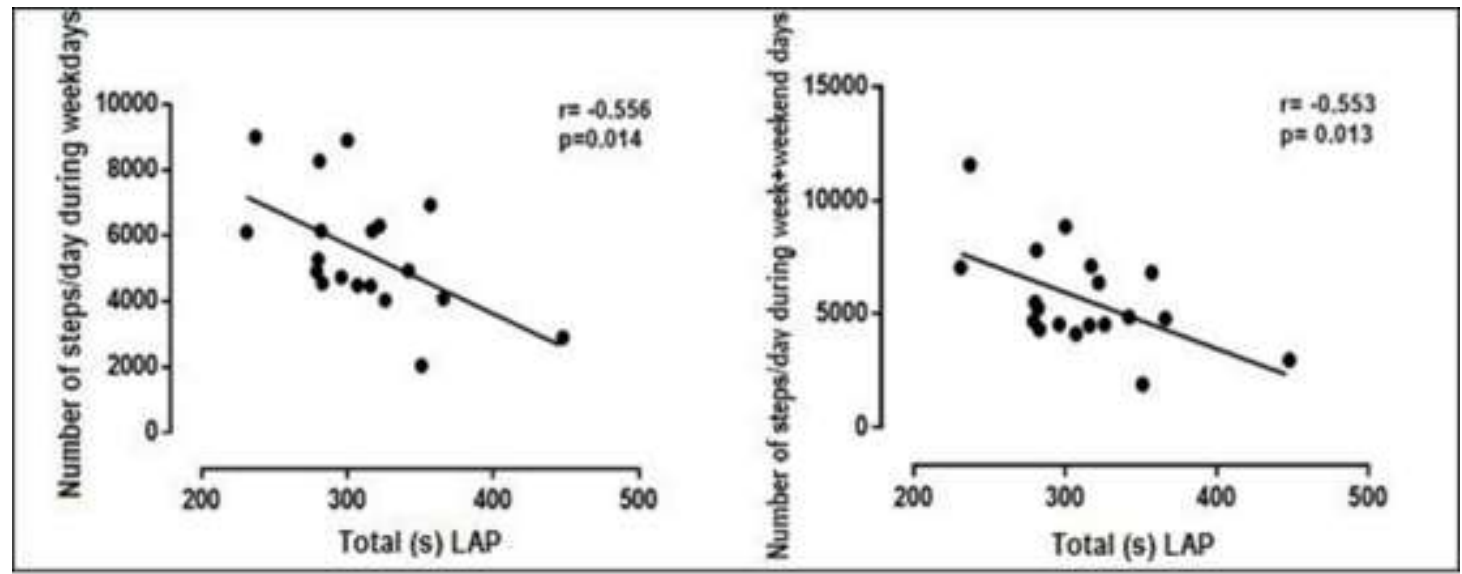

LAP: Londrina Activities of Daily Living Protocol. Source: This figure was developed by the authors.

The correlations between time spent in each LAP station (separately) and the patients' physical-functional assessments are described in Table 6. Correlations between LAP stations and IPAQ domains are described in Table 7.

Table 6. Correlations between physical-functional assessment and LAP stations.

\begin{tabular}{|c|c|c|c|c|c|}
\hline & $\begin{array}{c}\text { 1st } \\
\text { station }\end{array}$ & $\begin{array}{c}\text { 2nd } \\
\text { station }\end{array}$ & $\begin{array}{c}\text { 3rd } \\
\text { station }\end{array}$ & $\begin{array}{c}\text { 4th } \\
\text { station }\end{array}$ & $\begin{array}{c}\text { 5th } \\
\text { station }\end{array}$ \\
\hline \multicolumn{6}{|c|}{$\mathbf{N}^{\circ}$ steps weekdays } \\
\hline $\mathrm{r}$ & -0.030 & -0.514 & -0.113 & -0.456 & -0.241 \\
\hline $\mathrm{p}$ value & 0.903 & 0.024 & 0.646 & 0.050 & 0.320 \\
\hline \multicolumn{6}{|c|}{$N^{o}$ steps in the week+weekend days } \\
\hline $\mathrm{r}$ & -0.032 & -0.411 & -0.019 & -0.458 & -0.0122 \\
\hline $\mathrm{p}$ value & 0.898 & 0.081 & 0.937 & 0.048 & 0.619 \\
\hline \multicolumn{6}{|l|}{ TUG (s) } \\
\hline $\mathrm{r}$ & -0.328 & 0.585 & 0.111 & -0.181 & 0.512 \\
\hline $\mathrm{p}$ value & 0.136 & 0.004 & 0.623 & 0.419 & 0.015 \\
\hline \multicolumn{6}{|l|}{ T25 (s) } \\
\hline $\mathrm{r}$ & -0.301 & 0.760 & 0.165 & -0.143 & 0.522 \\
\hline $\mathrm{p}$ value & 0.173 & $<0.0001$ & 0.464 & 0.526 & 0.013 \\
\hline \multicolumn{6}{|c|}{ 6MWT (m) } \\
\hline $\mathrm{r}$ & 0.262 & -0.729 & -0.156 & 0.021 & -0.362 \\
\hline $\mathrm{p}$ value & 0.252 & $<0.0001$ & 0.500 & 0.929 & 0.107 \\
\hline \multicolumn{6}{|c|}{ 6MWT (\% predicted) } \\
\hline $\mathrm{r}$ & 0.049 & -0.759 & -0.115 & -0.360 & -0.256 \\
\hline $\mathrm{p}$ value & 0.832 & $<0.0001$ & 0.619 & 0.109 & 0.263 \\
\hline \multicolumn{6}{|c|}{ MFIS (points) } \\
\hline$r$ & 0.053 & 0.245 & 0.035 & 0.233 & 0.285 \\
\hline $\mathrm{p}$ value & 0.809 & 0.260 & 0.873 & 0.285 & 0.187 \\
\hline \multicolumn{6}{|c|}{ Barthel Total (points) } \\
\hline $\mathrm{r}$ & -0.138 & -0.402 & -0.528 & -0.170 & -0.366 \\
\hline $\mathrm{p}$ value & 0.529 & 0.057 & 0.010 & 0.439 & 0.086 \\
\hline \multicolumn{6}{|c|}{ MSWS-12 (points) } \\
\hline$r$ & 0.192 & 0.726 & 0.362 & 0.164 & 0.587 \\
\hline $\mathrm{p}$ value & 0.380 & $<0.0001$ & 0.089 & 0.455 & 0.003 \\
\hline \multicolumn{6}{|c|}{ EDSS (points) } \\
\hline$r$ & -0.049 & 0.715 & 0.419 & 0.061 & 0.417 \\
\hline $\mathrm{p}$ value & 0.823 & $<0.0001$ & 0.046 & 0.783 & 0.048 \\
\hline
\end{tabular}

LAP: Londrina Activities of Daily Living Protocol; $\mathrm{N}^{\circ}$ steps weekdays: average number of steps taken from Monday to Friday; $\mathrm{N}^{\circ}$ steps in the week: average number of steps performed 7 days a week; TUG: Timed up and go test; T25: Timed Walking of 25 feet; s: seconds; 6MWT (m): six-minute walk test; 6MWT (\% predicted): percentage of predicted 6-minute walk test performed by the patient; EDSS Expanded Disability Status Scale. MFIS: by the Modified Fatigue Impact Scale; Barthel: Barthel index; MSWS-12: Multiple Sclerosis Walking Scale - 12. Source: This table was developed by the authors. 
Table 7. Correlations between LAP stations and subjective assessment of physical activity, fatigue, activities in daily life and perception of walking.

\begin{tabular}{|c|c|c|c|c|c|}
\hline & 1st station & 2nd station & 3rd station & 4th station & 5th station \\
\hline \multicolumn{6}{|l|}{ IPAQ } \\
\hline \multicolumn{6}{|c|}{ Work (yes/no) } \\
\hline $\mathrm{r}$ & -0.373 & 0.507 & 0.308 & 0.202 & 0.292 \\
\hline $\mathrm{p}$ value & 0.079 & 0.014 & 0.153 & 0.356 & 0.176 \\
\hline \multicolumn{6}{|c|}{ Hours worked } \\
\hline $\mathrm{r}$ & 0.231 & -0.550 & -0.219 & -0.318 & -0.302 \\
\hline $\mathrm{p}$ value & 0.289 & 0.007 & 0.314 & 0.139 & 0.161 \\
\hline \multicolumn{6}{|c|}{ Years of study } \\
\hline $\mathrm{r}$ & 0.190 & -0.620 & -0.322 & -0.318 & -0.371 \\
\hline $\mathrm{p}$ value & 0.386 & 0.002 & 0.135 & 0.139 & 0.081 \\
\hline \multicolumn{6}{|c|}{ Health aspect } \\
\hline $\mathrm{r}$ & -0.265 & -0.582 & -0.501 & -0.161 & -0.339 \\
\hline $\mathrm{p}$ value & 0.221 & 0.004 & 0.015 & 0.464 & 0.113 \\
\hline \multicolumn{6}{|c|}{ Vigorous activities (days) } \\
\hline $\mathrm{r}$ & -0.383 & -0.058 & 0.197 & 0.017 & 0.042 \\
\hline $\mathrm{p}$ value & 0.071 & 0.793 & 0.367 & 0.937 & 0.851 \\
\hline \multicolumn{6}{|c|}{ Vigorous activities (min) } \\
\hline $\mathrm{r}$ & -0.270 & -0.382 & -0.214 & -0.261 & -0.362 \\
\hline $\mathrm{p}$ value & 0.213 & 0.072 & 0.326 & 0.229 & 0.089 \\
\hline \multicolumn{6}{|c|}{ Moderate activities (days) } \\
\hline$r$ & -0.242 & -0.288 & -0.038 & -0.325 & -0.093 \\
\hline $\mathrm{p}$ value & 0.265 & 0.182 & 0.865 & 0.130 & 0.674 \\
\hline \multicolumn{6}{|c|}{ Moderate activities (min) } \\
\hline $\mathrm{r}$ & 0.078 & -0.139 & 0.427 & -0.139 & -0.104 \\
\hline $\mathrm{p}$ value & 0.722 & 0.526 & 0.042 & 0.527 & 0.636 \\
\hline \multicolumn{6}{|c|}{ Walk (days) } \\
\hline $\mathrm{r}$ & -0.297 & -0.178 & -0.009 & -0.032 & 0.043 \\
\hline $\mathrm{p}$ value & 0.169 & 0.417 & 0.967 & 0.885 & 0.845 \\
\hline \multicolumn{6}{|c|}{ Walk (min) } \\
\hline $\mathrm{r}$ & -0.316 & -0.113 & -0.144 & -0.129 & 0.047 \\
\hline $\mathrm{p}$ value & 0.142 & 0.608 & 0.512 & 0.556 & 0.832 \\
\hline \multicolumn{6}{|c|}{ Sitting working days (min) } \\
\hline $\mathrm{r}$ & 0.259 & 0.020 & -0.210 & 0.506 & -0.203 \\
\hline $\mathrm{p}$ value & 0.233 & 0.929 & 0.335 & 0.014 & 0.352 \\
\hline \multicolumn{6}{|c|}{ Sitting on weekends (min) } \\
\hline $\mathrm{r}$ & -0.210 & -0.025 & -0.343 & -0.147 & -0.212 \\
\hline $\mathrm{p}$ value & 0.336 & 0.909 & 0.109 & 0.503 & 0.332 \\
\hline \multicolumn{6}{|c|}{ Barthel routine } \\
\hline $\mathrm{r}$ & -0.226 & -0.308 & -0.680 & -0.113 & -0.243 \\
\hline $\mathrm{p}$ value & 0.301 & 0.153 & $<0.0001$ & 0.609 & 0.264 \\
\hline \multicolumn{6}{|c|}{ Barthel stairs } \\
\hline $\mathrm{r}$ & -0.236 & -0.445 & -0.477 & -0.216 & -0.461 \\
\hline $\mathrm{p}$ value & 0.227 & 0.033 & 0.021 & 0.321 & 0.027 \\
\hline
\end{tabular}

LAP: Londrina Activities of Daily Living Protocol; IPAQ: International Physical Activity Questionnaire; Hours woeked: how many hours do they work a day; Vigorous activities (days): frequency of vigorous activity in the week in days; Vigorous activities $(\mathrm{min})$ : time in minutes spent in vigorous activity per day; Moderate activities (days): frequency of moderate activity on week in days; Moderate activities (min): time in minutes spent in moderate activity per day; Walk (days): frequency of days in the week that walk at least 10 continuous minutes; Walk (min): time in minutes spent walking each day; Sitting working days: time in minutes sitting on weekdays; Sitting on weekends: time in minutes that remains sitting on weekends; Barthel domains routine and stairs: Barthel Index. Source: This table was developed by the authors.

\section{Discussion}

This study suggests that the Londrina ADL Protocol, also known as LAP, can be used to objectively assess ADLs of individuals with MS. Due to the learning effect of the LAP in this population, it is recommended that two tests should be 
performed, preferentially by the same rater and the best test must be considered. This recommendation is confirmed when the asymmetric dispersion of the first LAP is observed (Figure 5). In addition, the LAP was significantly correlated with both the level of PADL and functional exercise capacity, which commonly reflect activities and movements performed in daily life (Cohen, Kessler \& Fischer, 1993; Einarsson, Gottberg, Fredrikson, Koch \& Holmqvist, 2006, Sandroff et al., 2012). It is worth mentioning that these correlations were moderate in the present study; however, the LAP is performed at usual speed and includes activities of the upper limbs, which evaluates ADLs not only related to gait, such as number of steps/day and the 6MWT. Moderate correlations regarding factors related to ADL, such as mobility and balance, were also found in the validation studies of the TUG test for elderly people (Podsiadlo \& Richardson, 1991) and for people with MS (Sebastião, Sandroff \& Learmonth, 2016); nevertheless, the TUG has been widely used to reflect functionality in these populations. In other words, the LAP seems to be reproducible and valid for individuals with MS.

Regarding the reproducibility of LAP in MS, there was a satisfactory ICC for intra and inter-rater reproducibility ( 0.86 and 0.72 , respectively). These results can be explained by the standardized recommendations with clear instructions on performing the LAP (Sant'Anna et al., 2017; Paes et al., 2017). Moreover, the LAP had a considerable learning effect (-6.6\%) and we suggested that the best of two tests should be considered. A similar learning effect was found with the 6MWT in people with Chronic Obstructive Pulmonary Disease (Hernandes et al., 2011). Despite recognized as reproducible, the 6MWT is performed twice worldwide to avoid overestimations of therapeutic intervention effects in this population.

In the present study, there was no correlation between the EDSS and the total time spent in the LAP, on the other hand, the EDSS was strongly correlated with the second station of the LAP $(r=0.726)$, where the individual should walk holding bags with $10 \%$ of their body weight. We hypothesized that the differences between LAP and EDSS may explain this finding. The EDSS prioritize activities related to gait and possibly do not represent the real causes of limitations in all aspects of ADLs (Machado, Almeida, Perla \& Scheffer, 2017; Cohen, Kessler \& Fischer, 1993). Whereas, the LAP was developed to directly reflects functionality when performing ADLs in the same way people do at their home. Therefore, we suggest that the LAP should be used in people with MS as a specific tool to assess ADLs which includes upper limbs while it becomes a complementary assessment since the EDSS reflects disabilities mainly considering lower limbs.

The number of steps was the assessment that best correlated with the LAP in individuals with MS $(r=0.556)$. This result corroborates with the ones found when the LAP was firstly developed, since it was correlated with the intensity of movement assessed by an accelerometer $(r=0.71)$ in people with COPD (Sant'Anna et al., 2017). In addition, we observed in the present study that the time spent performing the LAP (307 [281-342] seconds) in people with MS with an average age of $39 \pm 9$ years old was very close to the values obtained by healthy individuals aged between 50 and 59 years old (304 \pm 51 seconds) as demonstrated by Paes et al. (2017). In spite of being younger, individuals with MS perform similarly to healthy individuals at older ages possibly because people with MS may present physical limitations with the progression of the disease.

The total time spent performing the LAP was also moderately correlated with the 6MWT and did not show any correlation with other functional tests assessed in the present study. This result is due to the fact that those functional tests evaluate the maximum capacity of an individual to perform an activity and the maximum speed is required for the performance of tasks, while during the LAP activities should be performed at the usual speed (Paes et al.,2017). In fact, the speed of performing the LAP is a very positive differential of the test, since it aims to reflect the activities of daily living as close as possible to the individual's routine, which also explains the correlation of the LAP with the PADL (Bui, Nyberg, Maltais \& Saey, 2017).

By analyzing each station of the protocol separately, it was possible to identify some interesting correlations. The second station of the LAP was correlated with all functional tests objectively measured $(0.411<\mathrm{r}<0.760)$. All these activities are in some way related to the walking process, relying on their mobility and balance, situations that are essential for ADLs 
performance. Moreover, the fact that the first LAP station did not correlate with any proposed assessment can be explained by the way that the activity is performed since this is the only activity performed in a sitting position and that prioritizes upper limbs activities. In fact, one limitation of the study was the absence of a functional test validated for MS that evaluates upper limbs activities; however, it is known that the literature is scarce for these types of tests (Furlanetto, Correia \& Corso, 2020).

Another limitation of the study was the number of participants. However, we identified a statistical power of 0.92 considering 23 individuals with a mean difference between the $1^{\text {st }}$ and the $2^{\text {nd }}$ LAP of $24.35 \mathrm{~s}$ with a standard deviation of $32.87 \mathrm{~s}$ and the $\mathrm{P}<0,05$. In addition, this population is of low prevalence and difficult mobility, which can hinder its recruitment (The Multiple Sclerosis International Federation, 2020). Finally, responsiveness was not investigated in the present study, which makes it impossible to state that the LAP can be used for the clinical monitoring of the patient in relation to the development of the disease; however, we believe that LAP has great potential to become a widely used tool to detect clinical changes in people with MS, which include disease progression; therefore, future studies using the LAP in MS are also suggested to investigate other measurement properties, which include cutoffs with clinical applicability as well as the minimal clinical important difference (Koo \& Li, 2016)).

\section{Conclusion}

In general, the Londrina Activities of Daily Living Protocol was proved to be valid and reliable to be performed in people with multiple sclerosis with mild and moderate disability. Moreover, the best of two tests should be performed due to the learning effect.

Prospective studies investigating LAP responsiveness are recommended to better understand whether this test is sensitive to capture changes in the progression of MS, mainly related to functional disabilities.

This test can be considered as an objective way of evaluating activities of daily living, which includes the use of upper and lower limbs, and can be used both in research and in clinical practice

\section{Acknowledgments}

This manuscript is the final product of an abstract selected for presentation at Research Colloquium (2018) promoted by the Brazilian Committee of Treatment and Research in Multiple Sclerosis (BCTRIMS).

\section{References}

Britto, R. R., Probst, V. S., Andrade, A. F. D., Samora, G. A. R., Hernandes, N. A., Marinho, P. E. M., Karsten, M., Pitta, F., \& Parreira, V. F. (2013). Reference equations for the six-minute walk distance based on a Brazilian multicenter study. Brazilian J Phys Ther. 17(6):556-63.

Bui, K. L., Nyberg, A., Maltais, F., \& Saey, D. (2017). Functional tests in chronic obstructive pulmonary disease, Part 1: Clinical relevance and links to the international classification of functioning, disability, and health. Ann Am Thorac Soc. 14(5):778-84.

Cohen, R. A., Kessler, H. R., \& Fischer, M. (1993). The extended disability status scale (EDSS) as a predictor of impairments of functional activities of daily living in multiple sclerosis. J Neurol Sci. 115(2):132-5.

Crouter, S. E., Schneider, P. L., Karabulut, M., \& Bassett, D. R. (2003). Validity of 10 electronic pedometers for measuring steps, distance, and energy cost. Med Sci Sports Exerc. 35(8):1455-60.

Dancey, C. P. \& Reidy, J. (2007). Estatística sem matemática para psicologia: usando SPSS para windows. 3 edição. Porto Alegra - RS: Artmed, p. 608

Demeyer, H., Burtin, C., Van Remoortel, H., Hornikx, M., Langer, D., Decramer, M., Gosselink, R., Janssens, W., \& Trooster, T. (2014). Standardizing the analysis of physical activity in patients with COPD following a pulmonary rehabilitation program. Chest. 146(2):318-27.

Einarsson, U., Gottberg, K., Fredrikson, S., Von Koch, L., \& Holmqvist, L.W. (2006) Activities of daily living and social activities in people with multiple sclerosis in Stockholm County. Clin Rehabil. 20(6):543-51.

Ferreira, F. O., Lima, E. P., Vasconcelos, A. G., Lana-Peixoto, M. A., \& Haase, V. G. (2011) Velocidade de Processamento, Sintomas Depressivos e Memória de Trabalho: Comparação entre Idosos e Portadores de Esclerose Múltipla. Psicol Reflex e Crit. 24(2):367-80. 
Furlanetto, K. C., Correia, N. S., \& Corso, S. D. (2020) Upper limbs : how physically limited is your patient? J Bras Pneumol. 46(1):1-2.

Gosney, J. L., Scott, J. A., Snook, E. M., \& Molt, R. W. (2007). Physical activity and multiple sclerosis: Validity of Self-Report and Objective Measures. Mult Scler. 30(2):144-50.

Grant, S., Aitchison, T., Henderson, E., Christie, J., Zare, S., McMurray, J., \& Dargie, H. (1999). A comparison of the reproducibility and the sensitivity to change of visual analogue scales, Borg scales, and likert scales in normal subjects during submaximal exercise. Chest. 116(5):1208-17.

Hernandes, N. A., Wouters, E. F. M., Meijer, K., Annegarn, J., Pitta, F., \& Spruit, M. A. (2011) Reproducibility of 6-minute walking test in patients with COPD. Eur Respir J. 38(2):261-7.

Holland, A. E., Spruit, M. A., Troosters, T., Puhan, M. A., Pepin, V., Saey, D., McCormack, M. C., Carlin, B. W., Sciurba, F. C., Pitta, F., Wanger, J., Maclntyre, N., Kaminsky, D. A., Culver, B. H., Revill, S. M., Hernandes, N. A., Andrianopoulos, V., Camilo, C. A., Mitchell, K. E., Lee, A. L., Hill, C. J., \& Singh, S. J. (2014). An official European respiratory society/American thoracic society technical standard: Field walking tests in chronic respiratory disease. Eur Respir J. 44(6):1428-46.

Kaufman, M., Moyer, D., \& Norton, J. (2000) The significant change for the Timed 25-Foot Walk in the Multiple Sclerosis Functional Composite. Mult Scler J. 6(4):286-90.

Koo, T. K. \& Li, M. Y. (2016). A Guideline of Selecting and Reporting Intraclass Correlation Coefficients for Reliability Research. J Chiropr Med. 15(2):155-63.

Kurtzke, J. F. (1983). Rating neurologic impairment in multiple sclerosis: An expanded disability status scale (EDSS) [Internet]. Vol. 33, Neurology. p. 14441444. Available from: http://www.neurology.org/cgi/doi/10.1212/WNL.33.11.1444.

Lopes, J., Lavado, E. L., Kallaur, A. P., Oliveira, S. R. (2014). Avaliação da fadiga na esclerose múltipla: qualidade metodológica das versões originais adaptadas no Brasil dos instrumentos de autorrelato. Vol. 21, Fisioter. Pesqui. p. 392-397.

Machado, R.D., Almeida, R. M. M. de, Perla, A. da S., \& Scheffer, M. (2017). Esclerose Múltipla e diferentes escores da escala expandida do estado de incapacidade (EDSS): Funções executivas e qualidade de vida. Cuad Neuropsicol. 11(2):55-68.

Mansson, E., Lexell, J. (2004). Performance of activities of daily living in multiple sclerosis. Disabil Rehabil. 26 (10):576-85

Matsudo, S., Araújo, T., Matsudo, V., Andrade, D., Andrade, E., Oliveira, L. C., \& Braggion, G. (2001). Questionário Internacional de Atividade Física (IPAQ): Estudo De Validade E Reprodutibilidade No Brasil. Rev Atividade Física e Saúde. Vol. 6, p. 5-18.

Mendes, M. F., Tilbery, C. P., Balsimelli, S., Moreira, M. A., \& Cruz, A. M. B. (2001). Teste de destreza manual da caixa e blocos em indivíduos normais e em pacientes com esclerose múltipla. Arquivos de Neuro-Psiquiatria. Vol. 59, p. 889-94.

Mesquita, R., Wilke, S., Smid, D. E., Janssen, D. J. A., Franssen, F. M. E., Probst, V. S., Wouter, E. F. M., Muris, J. W. M., Pitta, F., \& Spruit, M. A. (2016). Measurement properties of the Timed Up \& Go test in patients with COPD. Chron Respir Dis. 13(4):344-52.

Minosso, J. S. M., Amendola, F., Alvarenga, M. R. M., \& Oliveira, M. A. C. (2010). Validação, no Brasil, do Índice de Barthel em idosos atendidos em ambulatórios. ACTA Paul Enferm. 23(2):218-223.

Molt, R. W., Cohen, J. A., Benedict, R. H. B., Phillips, G., LaRocca, N., Hudson, L. D., Rudick, R., \& Multiple Sclerosis Outcome Assessments Consortium (2017). Validity of the timed 25-foot walk as an ambulatory performance outcome meansure for multiple sclerosis. Ther Adv Vaccines. 23(5):704-10.

Nogueira, L. A. C., Baitelli, C., Alvarenga, R. M. P., \& Thuler, L. C. S. (2012). MSWS 12 - Tradução e adaptação transcultural da multiple sclerosis walking scale_12 para a lingua portuguesa do Brasil. Caderno de Saúde Publica, Rio de Janeiro. Vol. 2. p. 998-1004.

Oliveira-Kumakura, A. R. S., Bezutti, L. M., Silva, J. L. G., \& Gasparino, R. C. (2019). Capacidade funcional e de autocuidado de pessoas com esclerose múltipla. Rev. Latino-Am. Enfermagem [Internet]. 27: e3183. Available from: http://www.scielo.br/scielo.php?script=sci_arttext\&pid=S0104$11692019000100367 \& \operatorname{lng}=$ en.

Paes, T., Belo, L. F., da Silva, D. R., Morita, A. A., Donária, L., Furlanetto, K. C., Sant'Anna, T., Pitta, F., \& Hernandes, N. A. (2017). Londrina Activities of Daily Living Protocol: Reproducibility, Validity, and Reference Values in Physically Independent Adults Age 50 Years and Older. Respiratory Care. Vol. 62. p. 298-306. Available from: http://rc.rcjournal.com/lookup/doi/10.4187/respcare.05059

Pavan, K., Schmidt, K., Marangoni, B., Mendes, M. F., Tilbery, C. P., \& Lianza, S. (2007). Adaptação transcultural e validação da escala modificada de impacto de fadiga. Arquivos de Neuro-Psiquiatria. Vol. 65. p. 669-673.

Polman, C. H., Reingold, S. C., Banwell, B., Clanet, M., Cohen, J. A., Filippi, M., Fujihara, K., Havrdova, E., Hutchinson, M., Kappos, L., Lublin, F. D., Montalban, X., O'Connor, P., Sandberg-Wollheim, M., Thompson, A. J., Waubant, E., Weinshenker, B., \& Wolinsky, J. S. (2010). Diagnostic criteria for multiple sclerosis: 2010 Revisions to the McDonald criteria. Ann Neurol. 69(2):292-302.

Podsiadlo, D. \& Richardson, S. (1991). The Timed "Up \& Go": A Test of Basic Functional Mobilitv for Frail Elderlv Persons. J Am Geriatr Soc. 39(2):142-8.

Sandroff, B. M., Dlugonski, D., Weikert, M., Suh, Y., Balantrapu, S., \& Motl, R. W. (2012). Physical activity and multiple sclerosis: New insights regarding inactivity. Acta Neurol Scand. 126(4):256-62.

Sant'Anna, T., Donária, L., Furlanetto, K. C., Morakami, F., Rodrigues, A., Grosskreutz, T., Hernandes, N. A., Gosselink, R., \& Pitta, F. (2017). Development, Validity and Reliability of the Londrina Activities of Daily Living Protocol for Subjects With COPD. Respiratory Care. Vol. 62, p. 288-97. Available from: http://rc.rcjournal.com/lookup/doi/10.4187/respcare.05058 
Research, Society and Development, v. 11, n. 2, e19611225494, 2022

(CC BY 4.0) | ISSN 2525-3409 | DOI: http://dx.doi.org/10.33448/rsd-v11i2.25494

Sebastião, E., Sandroff, B. M., Learmonth, Y. C., \& Motl, R. W. (2016). Validity of the Timed Up and Go Test as a Measure of Functional Mobility in Persons with Multiple Sclerosis. Arch Phys Med Rehabil. 97(7):1072-7.

Spedo, C. T., Frndak, S. E., Marques, V. D., Foss, M. P., Pereira, D. A., Carvalho, L. D. F., Guerreiro, C. T., Conde, R. M., Fusco, T., Pereira, A. J., Gaino, S. B., Garcia, R. B., Benedict, R. H. B., \& Barreira, A. A. (2015). Cross-cultural adaptation, reliability, and validity of the BICAMS in Brazil. Clin Neuropsychol. 29(6):836-46.

The Multiple Sclerosis International Federation (2020). Atlas of MS, 3rd Edition. The Multiple Sclerosis International Federation (MSIF), September. 